\title{
Introducing the principles of Enhanced Recovery to a fractured neck of femur pathway - 5 years results and experience
}

\author{
Wainwright T W' 1 Immins $\mathrm{T}^{2}$, Middleton R $\mathrm{G}^{3}$ \\ Clinical Researcher in Orthopaedics, The Royal Bournemouth Hospital, and Visiting Fellow at Centre of Postgraduate Medical \\ Research and Education, Bournemouth University \\ Researcher in Orthopaedics, Bournemouth University \\ Director of Trauma, Poole Hospital, and Visiting Fellow at Centre of Postgraduate Medical Research and Education, Bournemouth University
}

$4^{\text {th }}$ ERAS UK Conference, $14^{\text {th }}$ November 2014 , Southampton. Hosted by the ERAS Society (UK)

\section{Introduction}

There is great potential for the principles of Enhanced Recovery to be successfully applied to fractured neck of femur (FNOF) pathways and help to improve clinical outcomes

\section{Aim}

To present the 5-year results and experience from Poole Hospital of applying the principles of Enhanced

Recovery to FNOF patients.

\section{Method}

A mixed-methods sequential explanatory design (QUAN emphasised) that consists of quantitative followed by qualitative data collected to evaluate the project.

Quantitative outcome data were extracted from Hospital Episode Statistics for 2008/09 to 2013/14 and analysed using a relative risk methodology. Relative Risk is the ratio of the observed number of outcomes to the expected number of outcomes and is case-mix adjusted. The NHS England average is calculated and 95\% confidence intervals are applied to determine statistical difference from unit performance to the equivalent casemix. Qualitative data were collected via staff interviews.

\section{Length of Stay - Relative Risk}

Quarterly trend from 2002/03 Q1 to 2013/14 Q3

Reduction of LOS over the last 5 years highlighted in box

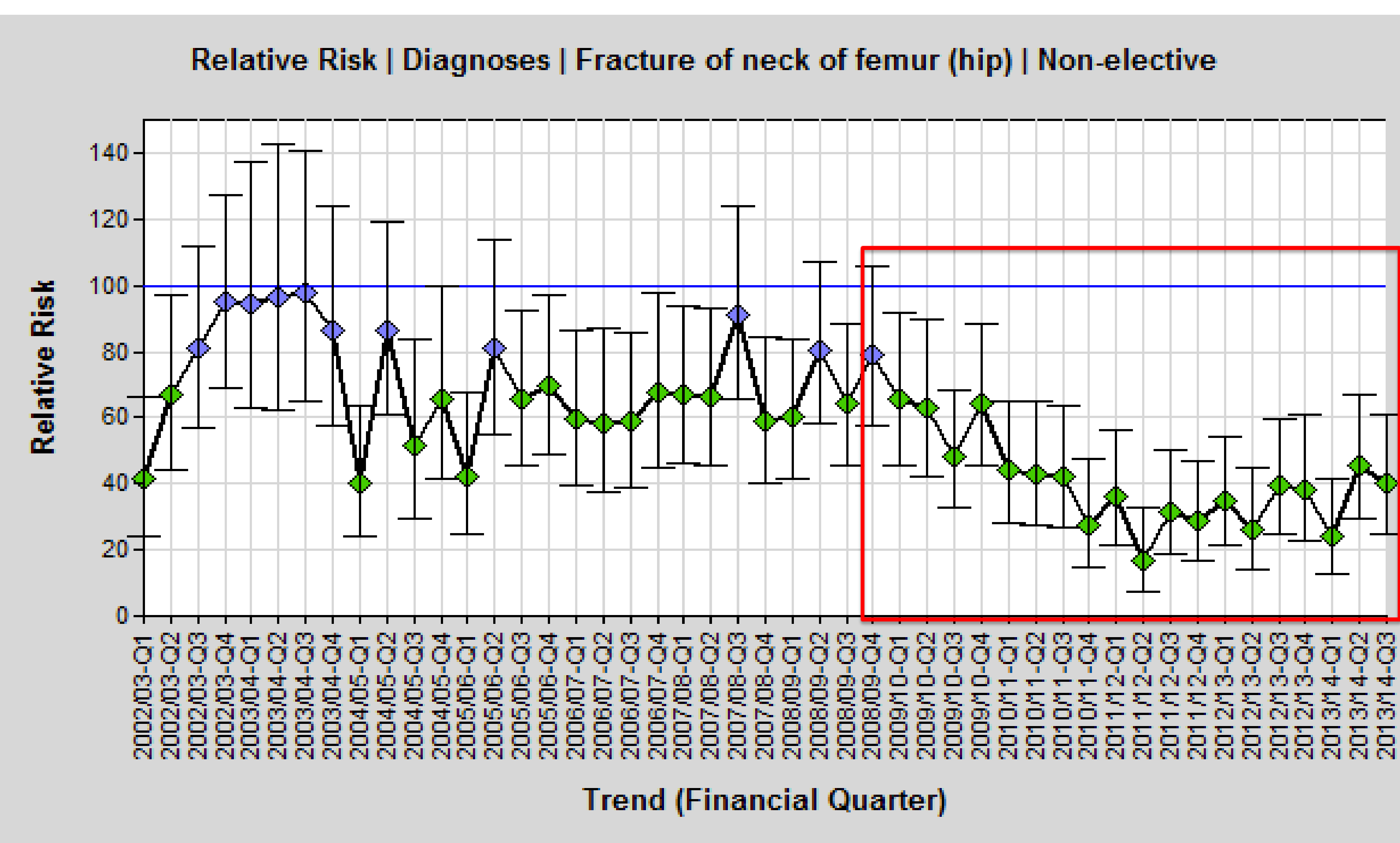

Relative Risk shows the ratio of the observed number of outcomes to the expected number of outcomes.

$\mathbf{R R}=[\mathrm{n}$ (observed) $/ \mathrm{n}($ expected $)] \times 100$

The benchmark figure (the NHS England average) is 100

-Values greater than 100 represent performance higher than the benchmark

-Values less than 100 represent performance lower than the benchmark

$95 \%$ confidence intervals are then applied to determine statistical difference to the same England case-mix.

The risk is calculated from the national dataset and case-mix adjusted for sex, age, deprivation, diagnosis group/procedure group, method of admission into hospital, comorbidity index and for certain conditions (respiratory) the seasonal variation

\section{Length of Stay}

Quarterly trend from 2002/03 Q1 to 2013/14 Q3

Reduction of LOS over the last 5 years highlighted in box

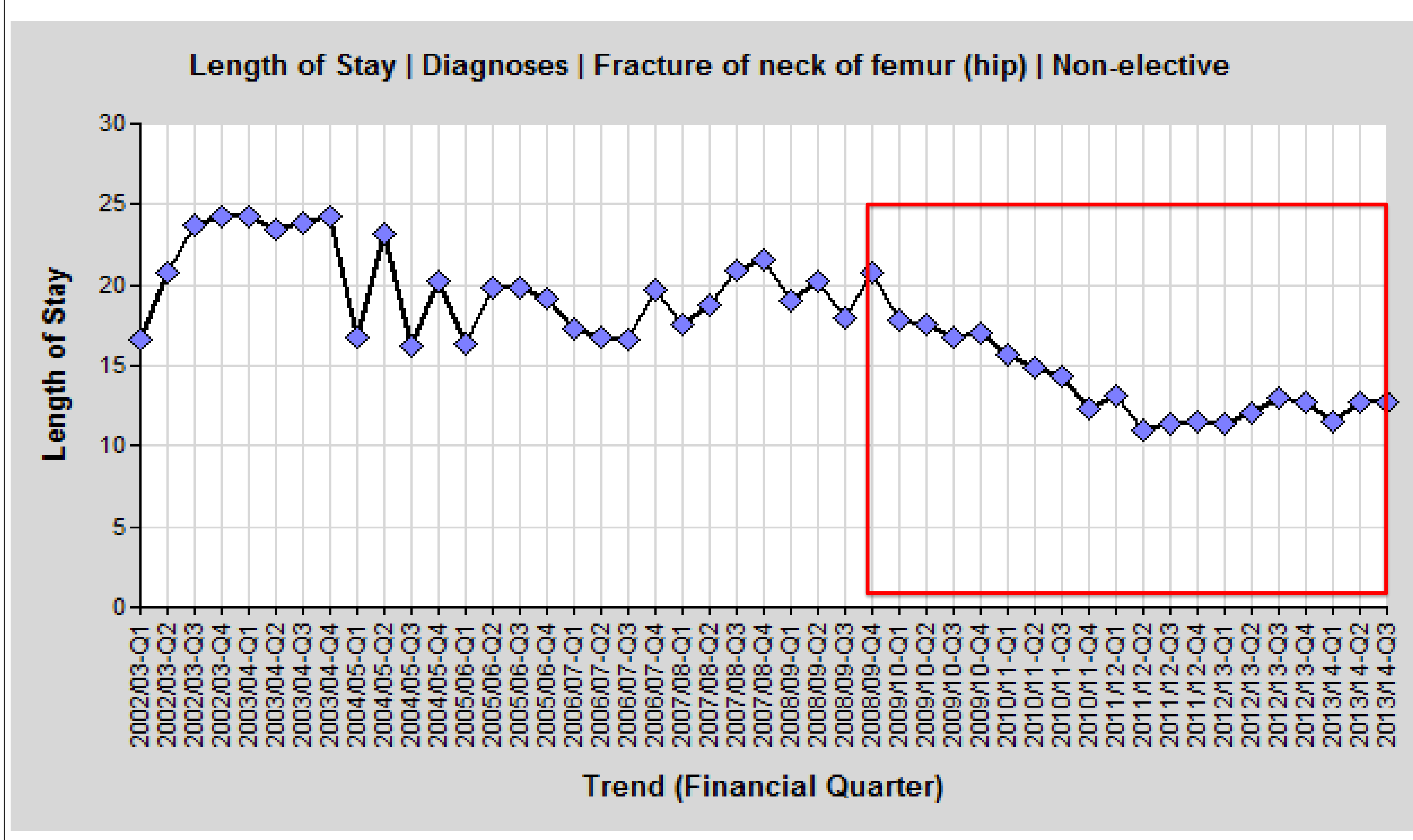

Results

A mean length of stay (LOS) of 12.3 days, a mortality rate of $5.7 \%$, a 28 -day re-admission rate of $10.2 \%$, and a discharge home rate of $55 \%$ achieved in the last year of the project are lower than expected for hospital case-mix Staff interviews highlighted that key factors for success were:

1. Collaborative practice across all teams

2. Input from the Department of Medicine for the Elderly

3. Changing the pre-operative mindset whereby instead of having to prove patients are fit for surgery, they are assessed as fit for surgery unless proven otherwise.

\section{Conclusions}

Enhanced Recovery can be successfully applied to FNOF patients in order to improve patient outcomes. However, implementation may be more challenging and take longer than for elective orthopaedic procedures.

\section{Extract from 2014 National Hip Fracture Database (NHFD)}

Poole Hospital NHS Foundation Trust (PHFT) submitted 855 cases to the NHFD. This represents a case ascertainment rate of $96.5 \%$ (estimated number of cases $=886$ ).

\begin{tabular}{|l|l|l|}
\hline NHFD Standard & Poole & National \\
\hline A\&E to orthopaedic ward in 4 hours & $58.2 \%$ & $47.4 \%$ \\
\hline $\begin{array}{l}\text { People with hip fracture have surgery on the day of, or the day } \\
\text { after, admission }\end{array}$ & $78.5 \%$ & $71.7 \%$ \\
\hline Assessment by geriatrician within 72 hours of admission & $99.5 \%$ & $81.6 \%$ \\
\hline Abbreviated mental test score (AMTS) assessment performed & $99.6 \%$ & $93.7 \%$ \\
\hline Specialist falls assessment & $99.9 \%$ & $94.6 \%$ \\
\hline Bone health medication assessment performed & $99.9 \%$ & $96.1 \%$ \\
\hline
\end{tabular}

